\title{
Wildlife Protection Law as a Barrier to Sustainable Drainage Wetlands and Pools in the UK and Elsewhere: A Proposal for Legislative Change.
}

\author{
Alan P Newman, Diane Whitehouse and Steve J Smith \\ Coventry University, Centre for Environmental Research and Consultancy \\ Priory Street, Coventry CV1 5FB, England
}

\begin{abstract}
SUDS systems represent a novel (or rediscovered) method of dealing with drainage from developed areas in a way which is likely to produce wildlife conservation benefits along with the flood control benefits that they primarily aim to achieve. Unfortunately in the UK the wildlife protection legislation, which should be seeking to maximise the conservation value produced by SUDS systems apparently, serves to discourage the use and management of such systems for this purpose. The major problem is the failure of the legislation to recognise that the use of SUDS systems by such protected species as the great crested newt (Triturus cristatus) represents an addition to the conservation baseline and that there is a case for providing an easy and pre-emptive legal mechanism to allow the maintenance and further development of SUDS systems. This should remove the fear that the drainage properties of the system will have to be compromised because of the presence of a population of organisms which may be given more protection than their local significance demands. This paper discusses these issues and proposes a possible solution which may also serve as a model in jurisdictions outside the UK.
\end{abstract}

\section{Introduction.}

The traditional approach to draining developed areas is reported as having a damaging impact on the environment (D'Arcy et al 2000). SUDS, an alternative approach to conventional drainage design and implementation, that replicates natural drainage and deal with runoff where it occurs, offers a wide range of techniques which can be adopted for most new and redeveloped sites to give a reduced environmental impact from surface water drainage (CIRIA, 2000). Despite the widely recognised advantage of SUDS there are, in the UK at least, certain problems with the law which act to discourage rather than encourage such developments. An earlier paper (Newman 2001) dealt with problems caused by the UK law on contaminated land. Legal problems associated with adoption of SUDS systems were pointed out by Honeyman and Baird (2000) and Ellis et al (2001) and indicated that public liability issues also have to be dealt with. Apostolaki et al (2001) indicated that public safety issues were prominent in the public perception. This paper deals with another commonly perceived problem associated with wildlife protection legislation.

As well as dealing with water quality and flooding issues, SUDS can improve amenity and biodiversity and indeed can be designed to enhance these properties (Jones and Fermor 2001). It is often this particular capability which is used to "sell" the idea to planners etc but it is this potential which also creates the problem which is 
the main subject of this paper. This paper originated as an idea developed from comments made by some participants of the First National Conference on Sustainable Drainage held in Coventry in June 2001. Here it became clear that there was a body of opinion that the potential of a SUDS system to encourage colonisation by organisms and development of ecosystems which are of conservation value, such that wildlife protection laws could at a later date inhibit the maintenance and further development of the site. This factor might also contribute to the adoption problems mentioned above. The aim of this paper is to examine how real these barriers are and to suggest how to overcome them.

\section{The Conservation Value of SUDS Elements}

SUDS systems have particular properties which could impart an enhanced conservation value. These include spatial variability in water depth which provides a variety of different habitats and, in particular, extreme variability in water depth and soil water content with respect to time. Gilbert and Anderson (1998) highlight the importance of careful design of ponds and wetlands to enhance biological diversity. The nature of linear features such as swales also makes them important potential conduits for the movement of valued species.

SUDS systems in the UK have been around for a relatively short period of time and thus despite the sometimes reported rather limited conservation value of SUDS systems (Powell et al 2001) there has not been the opportunity to see the long term conservation value of such systems. However, certain artificial water bodies, such as components of water supply systems, have been around for many years and have been shown both to develop important ecosystems and to be subject to similar problems with wildlife conservation laws (see below). Whilst the physical and ecological properties of SUDS elements as regards conservation enhancement (both with respect to themselves and to the watercourses which they protect) are important enough in their own right there are three particular aspects of them which have to be considered:

Firstly, any conservation value which is likely to develop on a SUDS site is dependent to some degree on the lack (or otherwise) of disturbance. If they are managed in such a way as to minimise disturbance the conservation value is likely to be greater (but possibly at the expense of amenity value).

Secondly, to obtain the greatest conservation benefit it is important that SUDS are considered holistically and that each element of the system is recognised as part of a network of habitats and wildlife corridors. The advice which has been given (SEPA 1998) is that where possible one should locate SUDS close to but not directly connected to existing wetland areas, so plants and animals can naturally colonise the new SUDS ponds without putting natural habitats at risk. Obviously, these first two actions depend on an intention to design and manage for optimum conservation value. As we will see later this may not be attractive from an operational or financial point of view under current legislation.

Finally, SUDS elements are new structures and only available for conservation benefit because they have been installed for drainage purposes and therefore any conservation value which accrues from there presence must, almost inevitably, be 
additional to what would have developed in their absence and unfortunately the current law in the UK fails to recognise this fact, treating the conservation value of SUDS as part of the natural system.

\section{Which Areas of Law Can Pose a Threat?}

There are in the UK, and in other parts of the world, a variety of nature conservation laws which might create real or perceived problems to those responsible for operating SUDS or for landowners with operating SUDS systems.

In many jurisdictions there are general development control laws which might come into force if an area, which has been drained using a SUDS system, is required to be redeveloped for a different use. This is the possibility which might threaten the most financial loss since, potentially, land with a considerable commercial value may become devalued. At the very least considerable delays and costs will ensue as regards the requirement for environmental assessments (EA) in the UK and the rest of the EU. The direct enforceability of the European Directive on EA is important here (see Berkeley $v$ Secretary of State for the Environment and Others 2000).

Space does not allow this aspect of the law to be covered in detail in this paper, rather it is concerned with more specific wildlife protection legislation. However, the interaction of planning law with wildlife protection legislation will be briefly mentioned, particularly involving Special Protection Areas (SPAs) and Special Areas of Conservation (SACs), which are established in the UK's implementation of two EU directives Directive on the Conservation of Wild Birds (79/409/EEC) (The Wild Birds Directive) and Directive 92/43/EEC (The Habitats Directive) and briefly with respect to Sites of Special Scientific Interest.

In considering wildlife protection laws we can divide them into two types:

- Firstly, there is the potential for a SUDS scheme, or part of it, to become designated for special protection as a result of its conservation value. Although, apparently a commonly held view this is certainly not an immediate threat to most SUDS systems and as we hope to show below the consequences are rarely as important as often perceived.

- The second area of law is that concerned with the protection of individual species. This is more likely to be a more realistic immediate threat. We must remember that these laws are usually triggered simply by the presence of the species without any need for designation by a regulatory body. In the UK we see the legal situation complicated by the fact that domestic legislation has been required to absorb European legislation and that this has not been done particularly elegantly.

\section{Protection by Habitat Designation.}

This paper will not cover designations as National Nature Reserves (NNRs) and Local Nature reserves (LNRs). These are of less interest to SUDS operators since although NNRs are provided with the highest level of protection available under UK law they are normally owned and managed by a statutory authority and must be managed 
appropriately to maintain their status and LNRs can only be designated as such by a local authority which has a legal interest in the land.

Sites of Special Scientific Interest (SSSIs) must be considered in relation to SUDS since they form the basic unit of UK protected area legislation to the extent that most higher designations are superimposed (sometimes quite loosely) onto existing SSSIs. Under the Wildlife and Countryside Act 1981(amended 1985) the government has a duty to notify as an SSSI any land which in its opinion is of special interest by reason of any of its flora, fauna, geological or physiographical features. SSSIs are nominated by a variety of bodies depending on which part of the UK the site is located. This body is known as the designating body and in England it is English Nature. An SSSI can be owned by anybody and thus the owner of a SUDS system might at some time in the future find themselves owning an area of land which has been designated as an SSSI. An SSSI is given protection against damaging operations, and any such operations must be authorised by the designating body. The status also affords the habitat a certain amount of planning protection and the consequences for the SUDS developer are thus compounded.

The Countryside and Rights of Way Act 2000 strengthened the law giving greater power to the designating body to enter into management agreements, to refuse consent for damaging operations, and to take action where damage is being caused through neglect or inappropriate management. Management agreements trigger compensation to be paid (under the Wildlife and Countryside Act 1981 Section 28M ss(2)) to the persons affected. In the past this has been on the basis of payment for net profits foregone but it is expected (Rodgers 2001) that in future management agreement compensation will be on the basis of positive payments for management activities carried out on the site.

Local Authorities and other public institutions also have a statutory duty to further the conservation and enhancement of SSSIs both in carrying out their operations, and in exercising their decision making functions, which includes planning decisions (Section 28G). Special provisions apply under section $28 \mathrm{H}$ as to how nature conservation bodies and section 28G authorities interact but essentially the ability to operate freely is limited as much for public bodies as private ones.

\section{Is Fear Of Designation as an SSSI Reasonable?}

In considering this question it must be remembered that if a site is to be designated it will be as a result of the habitat developing on a SUDS site in response to the routine management of that site. Any designation as an SSSI will be because a valuable habitat has been created, not least by the management and maintenance activities of the SUDS site which are accepted as being essential for maintenance of the drainage function (e.g. Fenner 2001, Bray 2001). The regulator will seek to maintain the habitat created and thus any formal management agreement is likely to reflect the routine maintenance of the site. Any works required in addition to the necessary works which would be involved in any event will be able to attract compensation payments. 
Operators must remember, however, that freedom to carry out actions outside the normal maintenance regime may be limited and that by allowing a system to become overgrown through lack of maintenance is possible to produce a site which develops great conservation value just at a time when maintenance is now essential and designation at this stage could well lead to problems. The moral here must be that routine maintenance to produce drainage conditions required should be rigorously adhered to if problems of a future SSSI designation is to be minimised.

It is also important to remember that in the event that a designation is made to a site any negotiations as to a management agreement should be carried out very carefully with the drainage requirements of the site incorporated as an integral part of the management plan. There is a possible argument that designation of a SUDS site as an SSSI could provide a mechanism for providing consent to maintenance activities in advance, under Section 28E ss(3) of the 1981 Act.

\section{Specific Responses to European Law}

The Wild Birds Directive requires EU member states to safeguard the habitats of migratory birds and certain particularly threatened birds. This includes the designation of Special Protection Areas (SPAs). This is designed to protect wild birds, and to provide sufficient diversity of habitats for all species so as to maintain populations at an ecologically sound level. It lists birds of special conservation concern requiring special conservation measures, and includes a selection of areas most suitable for them to be designated Special Protection Areas (SPAs). SPAs, or, more precisely, the birds within SPAs, have a limited amount of stronger protection than SSSIs as provided by the Conservation (Natural Habitats, etc.) Regulations, 1994. For areas important to organisms other than birds protection is provided by the Habitats Directive which (again implemented by the 1994 Regulations) gives rise to areas known as Special Areas of Conservation (SACs). English Nature's annual report (English Nature 2001) indicates that there are 212 SACs in England with 65 being added in 2000/01 (129,889ha). SACs have a very high degree of protection, certainly higher than a SSSI. For a SAC, if as a result of an application there is 'likely to be a significant effect' on the designated features of the SAC (i.e. almost anything, including things not within the boundaries of the SAC which might include work on a SUDS scheme bordering a SAC and the cumulative effect of several separate applications which might be appropriate in a SUDS situation) then the planning authority must obtain an 'appropriate assessment' of the application and its likely effect. Unless this assessment shows that the application will have no negative impact then the freedom to accept an application is much more constrained than it is for SSSIs.

A recent case (Royal Society for the Protection of Birds $v$ Secretary of State for Scotland) indicates to us that operations on SACs and SPAs cannot be permitted on the grounds that the overall population of the species affected will not be substantially impacted by the action unless the specific population on the designated site is not impacted (see also Rodgers 2001). 


\section{Designation of Artificial Structures}

SUDS systems are artificial structures and the question might be asked as to whether designation of artificial structures are possible or likely. However, the fact that artificial structures can have conservation value and can be designated as such is clearly demonstrable in the UK. Good examples are the many quarries that are designated as SSSI, wetland examples are also common, with gravel pits and reservoirs being designated sites. Rutland Water, in the UK, is a reservoir that is a SSSI and a SPA. Many of these sites are designated because of wildfowl populations but it is also possible for an artificial habitat to be designated for certain species (e.g. butterflies and orchids for quarries) and for certain community type (e.g. limestone grassland in railway cuttings). The relatively small size of SUDS systems means that they are less likely to be designated on their own as SACs or SPAs. However, in 1997 Denby Grange Colliery Ponds a 19.1ha site in West Yorkshire near to a disused colliery was proposed for SAC designation, on the basis that the site was an important breeding site for great crested newts (Triturus cristatus)(species nomenclature follows cited reference or statute).

\section{Protection at a Species Level}

The Wildlife and Countryside Act 1981 is also the principle mechanism for the legislative protection at a species level in Great Britain. This legislation is the means by which the 'Bern Convention' and previously mentioned European Directives (along with other action taken under the European Communities Act) when this applies to protection at a species level it involves Part I of the Act.

The Wildlife and Countryside Act 1981 also prohibits the release of non-native species into the wild (Section 14). This is to prevent the release of exotic species that could threaten our native wildlife. It is worth noting some populations of non-native species relevant to SUDS operations, such as the marsh frog (Rana ridibunda), alpine newt (T.alpestris) and, more recently the American bullfrog ( $R$. catesbeiana) have become established in the wild in Britain. The legislation does not prohibit capturing and keeping these animals but it makes re-releasing them an offence. Managers of SUDS systems in the UK should be aware that any of these species captured from their systems should not be re-released and that the planting or fostering of certain exotic plant species is also illegal.

Everything prohibited by the Wildlife and Countryside Act 1981 can be made legal by licensing by the proper authority. Section 16 provides a mechanism for 1icensing actions that would otherwise be unlawful; different statutory agencies are responsible for 1icensing activities depending on the reason for doing them. For example (in England) English Nature is generally responsible for licensing most activities done for scientific study, educational reasons or for photography or conservation. DEFRA issues licenses for public health and protection of property.

Since the passing of the Wildlife and Countryside Act 1981 there have been amendments to the lists of protected species, through Variations to the Schedules Orders. There is a statutory five yearly review of those Schedules which list protected species undertaken by the statutory conservation agencies. Changes can be made by 
the Secretary of State at any time if it is considered necessary because of a threat of extinction or in response to international obligations and thus there is a possibility that even without a change in the real conservation value in an established SUDS system the burden of wildlife protection can be increased over a short period of time because of changes in official perception of a particular species' importance.

\section{Protection under Part I of the 1981 Act}

Sections 1 to 8 relate to protection of birds. Section 1 prohibits the intentional killing, injuring or taking of any wild bird and, importantly, damage or destruction of a nest or eggs. There are additional penalties for offences relating to birds on Schedule 1.The Secretary of State is allowed (under Section 3) to designate areas of special protection (sanctuaries) to provide further protection to birds and even prohibit disturbance or restrict access. Although the occupation of a site by a protected species is a fear anticipated by UK SUDS operators the possibility that the site is occupied by a relatively common nesting bird is far greater (although usually less of a problem if maintenance is scheduled correctly).

Other animals are covered by Section 9 which prohibits the intentional killing, injuring or taking, the possession and the trade in wild animals listed on Schedule 5. In addition, places used for shelter and protection are safeguarded against intentional damage, destruction and obstruction and animals protected under the relevant part of Section 9 must not intentionally be disturbed whilst occupying those places. Clearly one can see that management of a SUDS system could be severely affected by this problem.

Section 13 identifies measures for the protection of wild plants. It prohibits the unauthorised intentional uprooting of any wild plant species (not a particular problem to the SUDS operator who will presumably have legal authority) but more importantly forbids any uprooting or destruction of plants listed on Schedule 8.

\section{European Protected Species}

From March 2000, the law concerning the protection of certain species has been interpreted in a different way in England and Wales (this change does not affect Scotland where the law has generally been interpreted in this way since 1994). This followed a complaint to the European Commission in 1998 concerning the protection of great crested newts (T.cristatus). The Conservation (Natural Habitats etc.) Regulations 1994 (implementing the Habitats Directive) makes it an offence deliberately to kill, or disturb a European Protected Species, or to damage or destroy the breeding site or resting place of an animal on the European list. Prior to 2000 it was the practice in England and Wales for anyone who wished to undertake an operation that would breach these regulations to apply for a license which was normally granted if it could be shown that the protected species could be satisfactorily relocated to another place, or some other mitigation (such as habitat creation) could be undertaken to compensate for the damage to the species or its habitat. The Commission issued a formal Letter of Notice in April 1999 stating that Article 16(1)(a) was not being complied with and the new interpretation of the law was 
published on 19 May 2000. Since March 2000 all applications for a licence are measured against a different set of criteria.

For a licence to be issued these three tests must be satisfied:

- That there is 'no satisfactory alternative';

- the derogation (i.e. any permission/licence granted) is 'not detrimental to the maintenance of the populations of the species concerned at a favourable conservation status in their natural range';

- That the development is 'in the interests of public health and public safety, or for other imperative reasons of overriding public interest, including those of a social or economic nature and beneficial consequences of primary importance for the environment';

The following species which might be encountered in a SUDS system are European Protected Species.

Great Crested Newt (T. cristatus)

Creeping Marshwort (Apium repens)

Yellow Marsh Saxifrage (Saxifraga hirculus)

Floating-leaved water plantain (Luronium natans)
Natterjack Toad (Bufo calamita)

Slender Naiad (Najas flexilis)

Fen Orchid (Liparis loeselii)

\section{Other Jurisdictions}

Since UK wildlife legislation is now largely dependent on European legislation it is likely that throughout the European Union similar problems can occur to those in the UK. The extent to which the wildlife protection law forms a serious problem for SUDS operators will depend both upon the way in which the EU law is incorporated into domestic legislation and on the administrative provisions applied.

Outside the EU there are also wildlife protection legislation which might have the same effect. In Australia, for example there is The Commonwealth Environment Protection and Biodiversity Conservation Act 1999 and in the USA Rodriguez et al (2001), although not mentioning SUDS directly, they report that "Public and scientific opinion is divided over the current Endangered Species Act (ESA). Many private landowners and real-estate developers see it as a major impediment to economic progress. A detailed comparative study of the affects of wildlife protection laws on SUDS systems in non-EU jurisdictions would be most useful.

\section{Argument for a Different Approach for SUDS Systems.}

If rare species were randomly distributed then the national, or indeed international importance of a new colonisation of a SUDS system would be very different to what it is in reality. Similarly, if rare species were randomly distributed the chances of colonisation of a particular SUDS scheme by a particular rare species would be considerably reduced. However, this is not the nature of rare species distribution. It is commonly observed that although certain species may be rare, in that they now occur in very few locations, they are often locally very common. This is not a UK 
phenomenon and Rodriguez et al (2001) reported non-random patterns in the distribution of endangered animals and plants in the USA.

What this means is that in certain areas of a country the likelihood of protected organisms being available for colonisation is high and also that the value of SUDS systems in the short to medium term to act as conduits to allow such species to extend their range is very high. It also indicates that in relation to overall biodiversity the occasional loss of a particular organism from a SUDS site due to essential maintenance is not particularly great (it is likely to be temporary since the conditions which attracted the species in the first instance will still remain and there is potential for colonisation, not least from other parts of the system). This phenomena is magnified when organisms are designated on a European basis. The great crested newt (T.cristatus) is protected as a Schedule 2 European species and yet it is still widespread in Britain with an estimated 18,000 ponds containing these animals (though less so in Scotland where there are fewer than 1000 individuals) (UK Biodiversity Action Plan 2001). This species probably epitomises more than any other the fears of wildlife conservation laws coming into action in relation to SUDS that we seriously contemplated the title "The Great Crested Newt Problem” for this paper.

Another factor which should be considered is the effect of the Biodiversity Action plans which have been developed for both species and habitats. Many of these involve plans for extending the range of various species through habitat creation and relocation. A SUDS site may be some way from a current source of colonisation but this could well change particularly if nearby ponds have at one time been occupied by a protected species. Operators of SUDS who wish to avoid future problems may also need to take care that their own water bodies are not used for relocation of rare species either legally or illegally.

It is also clear that the design and operation of SUDS systems can have considerable effect on the general benefit as regards the extent to which these benefits will accrue and that if the biological advantage of SUDS is to be maximised it is necessary to overcome all the barriers to their implementation. If any new technology is to be widely adopted by society there are a number of conditions that need to be met. This includes an acceptance that the technology is capable of achieving the stated performance targets but there are other requirements including requirements for operational ruggedness, safety, and financial acuity. There is also, however, a requirement that the legal situation is correct.

\section{The Role of the Law}

The law is the means by which government policies are translated into action and, more importantly, a means by which the messages of approval or disapproval by society of that technology are transmitted to those who are required to make decisions. If it is perceived that society has priorities which are more important than the adoption of a particular technology it will not encourage the adoption of these technologies. This is probably the greatest contribution that new laws could make to SUDS systems. 
If a decision is made by a government to adopt a particular policy (such as encouraging SUDS in preference to conventional systems) clearly, it can do so administratively through issuing guidance to regulators and similar means. However, unless great care is exercised in the use of administrative means to implement government environmental policies they can be subject to legal challenges by individuals or groups (see Hilson 2001) aggrieved either by the policy itself or individual decisions and who have sufficient standing in bringing a case under environmental legislation ( $R v$ Inspectorate of Pollution ex parte Greenpeace Ltd). In other jurisdictions the standing of pressure groups are very variable both from jurisdiction to jurisdiction and within jurisdictions over time. For example, the Friends of the Earth $v$ Laidlaw Environmental Services case has shown a recent shift in the USA towards a more liberal approach to standing. Given the ability of SUDS to encourage the development of populations and habitats which generate vociferous champions in the form of environmental action groups the possibility of enforcement action being forced on regulators wishing to take a pragmatic approach by public pressure or even legal challenges is significant. For example, a local pressure group is currently using the presence of great crested newts (T. cristatus) as part of a campaign against development (Gee Cross Action 2001).

It is therefore important that we recognise the need to ensure that the legal systems of the countries in which SUDS is being promoted should be such that they do not act as a disincentive towards SUDS. The use of the law to specifically protect investment in an environmentally friendly technology is not without precedent (Newman 2000).

\section{What Characteristics Should Such a Legal Framework Have?}

The first requirement is one of certainty or at least predictability. One of the most important aspects of any successful legal system is that a person who plans an investment today can be sure that a legal right to benefit from the investment will, once acquired, be maintained. This might be in perpetuity or there may be a minimum time within which such legal rights will be maintained.

The second is the need for a purposive approach to the law. Legislation should do what it intends to achieve and not through poor drafting actually impede some of it's own intentions. This latter is the problem with the current UK wildlife legislation with respect to SUDS which is compounded by the fact that wildlife legislation originally drafted with particular objectives in mind has been adapted at a later date to comply with European Directives. Whilst the range of wildlife legislation is aimed at enhancing biodiversity through either the protection of habitats or of species it places, at the very least, a perceived barrier in the minds of those who should be encouraging both the introduction of SUDS and the management of the systems for maximum conservation value. Despite the position statement of English Nature "Managing floodplains to reduce flood risk and enhance biodiversity" (English Nature 2001b) which states English Nature's recognition that SUDS can contribute to both they seem to be content to treat SUDS in the same way as any other site, failing to recognise the fact that a properly managed SUDS network will provide far more conservation value than any single site. 
A person who is worried that his site will be designated as being of special conservation value if he manages it in a way which is ecologically sound rather than simply effective as a drainage system and aesthetically pleasing will not be encouraged. Similarly a person who worries that a certain species might be established within a SUDS system might be tempted to design and manage the system so as to discourage its establishment of that species. Questions have even been asked as to whether it might be possible to stock a balancing pond with a predator to prevent establishment of the great crested newt (T.cristatus ).

Thirdly, there is the need to address the moral problem which is normally exemplified by its negative form, the "polluter pays principle" in which it is widely accepted that a person who damages the environment should pay the cost of restoring the harm caused. How then can society expect that a person who has enhanced the environment should be required to bear the cost of maintaining or eventually restoring to its former enhanced state those parts of the environment which he has already paid the cost of enhancing?

Widely held fears of problems caused by wildlife protection legislation will inevitably result in less SUDS systems and in those systems that are in operation being managed in such a way that conservation value is minimised rather than maximised. This would even apply if planning practice were to change such that SUDS systems were mandated upon developers. The operators would still have a great opportunity to choose or not to choose to manage sites in a conservation friendly way. Similarly, if a system is proposed in an area which is the site of locally common population of a nationally rare species the system is under threat of an invasion by the protected species which could seriously inhibit the ability of the operator to carry out maintenance. The perception of this prospect because of the way in which the law is understood could be equally as damaging as a real threat.

\section{Possible Solutions}

A possible protection from this legal threat might be drawn from other types of legislation which recognises that environmentally or socially unfriendly activity must be permitted from time to time on the basis of the benefit to the greater good. For instance the noise from construction sites is regulated in the UK under the Control of Pollution Act 1974 which enables the regulator to specify noise limits and modes of operation which must be complied with. Importantly, the Act also allows the construction site operator to obtain some certainty that what they do will not be interrupted by action from the regulators because of noise. This works by allowing the site operator to require the regulator to state in advance what he will require of the operator. We can imagine this applied to a SUDS system, whereby, at the planning stage for a SUDS system a SUDS operator can make an application to a designating body to state what relocation activities would be permitted should a protected species be discovered on site at a time when maintenance or redevelopment is required. We could look on this as a consent for an activity prohibited by some wildlife protection legislation but issued in advance before the protected species or habitat becomes established in the location. The designating body would then be faced with a decision as to whether to refuse to grant a prior approval (thus forgoing the conservation value which would accrue) or to grant the application and give some degree of certainty to 
the operator that his ability to operate and maintain his system. A decision to approve the action would be made in advance of the presence of the protected species and would thus be much less likely to attract attention of local environmental pressure groups.

An alternative or addition to a case by case prior approval system might be a general recognition in the law that actions taken to maintain SUDS systems will not constitute an offence under wildlife protection legislation. This would need to be backed up by ensuring that the SUDS systems are operated in an appropriate way. One way would be to include in the legislation a provision for codes of practice indicating how the operator must maintain and operate the site in a certain way, to the benefit of conservation. Many examples of similar types of legislation exist in the UK. Although codes of practice have no force of law compliance with the codes can be used as a defence in the event of prosecution. A code of practice for SUDS might include timing of operations outside certain months, design features, minimum and maximum water levels, provision of refuges and/or a well planned cycle of maintenance but considerably imaginative drafting of legislation would be required if this is to work. A code of guidance for SSSIs issued under section 33 of the 1981 Act has been in existence for some time (Anon 1982). This is not, however, an adequate document as regards the needs of managing SUDS systems, nor does it have the same force in law as an Approved Code of Practice.

One question, with respect to the UK, is whether or not any proposals to change UK law would be allowed under European law or whether changes at a European level will be required first. This would also be of relevance in considering responses to other European jurisdictions. Obviously, this would apply only to designated sites or European listed species. If a site hosts a priority species development on a site can only be permitted if there are overriding considerations connected with human health, public safety or "beneficial consequences of primary importance for the environment”. How this might be interpreted if the legislators made the case that it was important to encourage the wider adoption of SUDS systems with consequential environmental benefits is unknown but possibly the importance of SUDS systems to flood prevention would be taken into account. In EC Commission v Federal Republic of Germany it fell to be determined whether dyke building operations which had resulted in both deterioration in the living conditions of protected birds and a loss of land area of considerable ecological importance had been carried out in contravention of the Wild Birds Directive. It was held that the work had been carried out with appropriate justification and it is notable that the fact that some positive environmental benefits also accrued was taken into account in the decision. However, it is probably the case that any decision to modify UK legislation so as to give protection to SUDS systems would at least be subject to challenge and possibly a European approach to the problem may be needed.

\section{Conclusions}

The particular approach to protecting SUDS from the undesirable effects of wildlife protection legislation will depend upon the particular form of legislation which is in place but in the UK it is suggested that a good approach would be: 
- Some form of SUDS operations licence which protects the SUDS scheme from designation as an SSSI or similar protected status. This would have as its purpose the maximisation of all the conservation value available from a national network of SUDS systems without imposing a real or perceived legal barrier to actions likely to attract and protect rare species or create important habitats.

- Linked to this could be a licence condition to operate within a given set of management constraints possibly defined by an Approved Code of Practice. If complied with this would be seen as a defence against prosecution for breach of part 1 of the Wildlife and Countryside Act 1981 on all sites previously designated as SUDS systems. Research is clearly needed in this area since any code of practice needs to be established from a good scientific basis.

Clearly, a number of options are available and the choice must be subject to debate within each jurisdiction. The first problem, however, is to convince legislators that there is a problem and a need for a change in the law. The only way to achieve this is for the problems to be pointed out at every opportunity and for full advantage to be taken of any consultation processes available in particular jurisdictions.

\section{References}

Anon (1982)(first publication date), Sites of Special Scientific Interest Code of Guidance, HMSO, London

Apostolaki S., Jefferies C., and Souter N.(2001), Assessing the Public Perception of SUDS at Two Locations in Eastern Scotland, Proc. First National Conference on Sustainable Drainage, Coventry, UK, 18-19 June, pp28-37.

Bray R.(2001), Maintenance of Sustainable Drainage-Experience on Two EA Demonstration Sites in England, Proc. First National Conference on Sustainable Drainage, Coventry, UK, 18-19 June, pp81-92.

CIRIA (2000) Sustainable Urban Drainage Systems - Design Manual for England and Wales. CIRIA

D’Arcy, B.J., Ellis, J.B., Ferrier, R.C., Jenkins, A., and Dils, R (2000) Diffuse Pollution Impacts: The Environmental and Economic Impacts of Diffuse Pollution in the UK. Terence Dalton Publishers, Lavenham, Suffolk.

Ellis J.B.,Shutes R.B.E.,Revitt D.M.,Forshaw M and Winter B(2001),SUDS and Constructed Wetlands: How Compatible Are They, Proc. First National Conference on Sustainable Drainage, Coventry , UK, 18-19 June, pp147-158.

English Nature (2001a)

www.english-nature.org.uk/pubs/publication/PDF/annualreport102.pdf (30 Aug 2001)

English Nature (2001b) www.english-nature.org.uk/news/statement.asp?ID=35 (29

Dec 2001) 
Fenner R.A.(2001), Is Urban Drainage Sustainable Without Improving Maintenance, Proc. First National Conference on Sustainable Drainage, Coventry , UK, 18-19 June, pp81-92.

Gee Cross Action (2001) www.geecrossaction.org.newtlaw.html (20 Dec 2001)

Gilbert O.L., and Anderson P.,(1998) Habitat Creation and Repair , Oxford University Press, Oxford.

Hilson C (2001), Greening Citizenship:Boundaries of Membership and the Environment,J Env Law ,13(3) , pp335-338

Honeyman M.J.and Baird I.A. (2001) , Newhall Valley Water Management Strategy, Proc. First National Conference on Sustainable Drainage, Coventry , UK, 18-19 June, pp10-16.

Jones, M., and Fermor, P. (2001), Sustainable Drainage Systems-Maximising Opportunities to Meet Biodiversity Targets, Proc. First National Conference on Sustainable Drainage, Coventry , UK, 18-19 June, pp38-37.

Newman A.P. (2000), Small Scale Wind and Solar Energy Systems: Access to Resources Under Irish and English Law, Irish Planning and Environmental Law Journal, 2000, 7, (4) pp139-147

Newman A.P. (2001) Liabilities In English Law Arising From Infiltration Of Stormwater. . Proc. $4^{\text {th }}$ International conference on innovative technologies in urban drainage (Novatech). Lyon, France, pp375-382

Powell A., Biggs J , Williams P , Whitfield M.,Logan P., and Fox G. (2001), Biodiversty Benefits From SUDS- Results and Recommendations, Proc. First National Conference on Sustainable Drainage, Coventry , UK, pp47-57.

Rodgers C.P. (2001), Managing Natura 2000: Priorities for Implementing European Wildlife Law, J.P.L, March 2001, pp 265-283.

Rodriguez J.P., Roberts W.M. and Dobson A (2001) Where are Endangered Species Found in the United States? http://www.umich.edu/ esupdate/library/97.0304/rodriguez.html (Dec 28 2001)

SEPA (1998) Habitat Enhancement Initiative- Enhancing Sustainable Urban Drainage Systems For Wildlife.

http://www.sepa.org.uk/publications/leaflets/hei/SUDS\%20(HEI)\%20leaflet2.pdf (Dec 28, 2001)

UK Biodiversity (2001) UK Biodiversity Action Plan, www.ukbap.org.uk/plans/species/NBNSYS0000005053.htm (29 Dec 2001)

\section{Cases Cited}


$R v$ Inspectorate of Pollution ex parte Greenpeace Ltd (No2) [1994] 4 All ER 329

Berkeley v Secretary of State for the Environment and Others (2000) JEL 13(1) 89105

EC Commission v Federal Republic of Germany (1991) Times 20 March ECJ

Friends of the Earth v Laidlaw Environmental Services 120S Ct 693 (2000)(Su Ct US)

Royal Society for the Protection of Birds v Secretary of State for Scotland [2000] SLT 1272. 